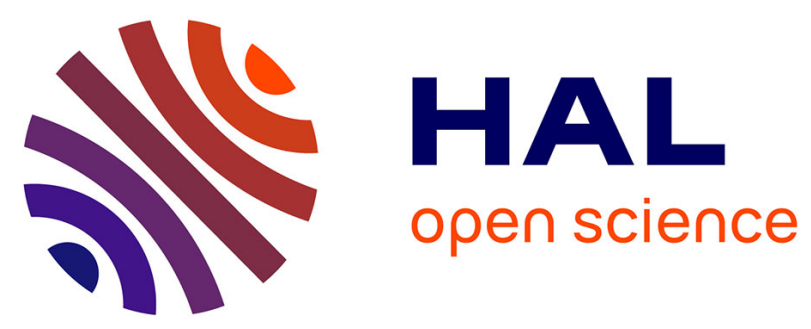

\title{
Nature, ecology and chemistry: An unusual combination for a new green catalysis, ecocatalysis
}

\author{
Pierre-Alexandre Deyris, Claude Grison
}

\section{To cite this version:}

Pierre-Alexandre Deyris, Claude Grison. Nature, ecology and chemistry: An unusual combination for a new green catalysis, ecocatalysis. Current opinion in green and sustainable chemistry, 2018, 10, pp.6 - 10. 10.1016/j.cogsc.2018.02.002 . hal-01938026

\section{HAL Id: hal-01938026 \\ https://hal.umontpellier.fr/hal-01938026}

Submitted on 13 Oct 2020

HAL is a multi-disciplinary open access archive for the deposit and dissemination of scientific research documents, whether they are published or not. The documents may come from teaching and research institutions in France or abroad, or from public or private research centers.
L'archive ouverte pluridisciplinaire HAL, est destinée au dépôt et à la diffusion de documents scientifiques de niveau recherche, publiés ou non, émanant des établissements d'enseignement et de recherche français ou étrangers, des laboratoires publics ou privés.

\section{(이) $\$$}

Distributed under a Creative Commons Attribution - NonCommercial - NoDerivatives| 4.0 


\section{Accepted Manuscript}

Nature, Ecology and Chemistry: an unsual combination for a new green catalysis, Ecocatalysis

Pierre-Alexandre Deyris, Claude Grison

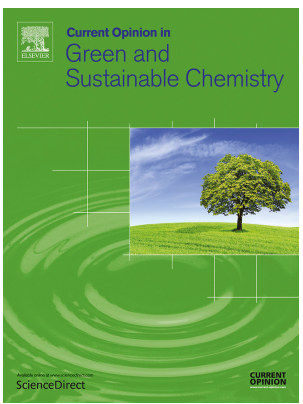

PII:

S2452-2236(17)30082-2

DOI: 10.1016/j.cogsc.2018.02.002

Reference: COGSC 115

To appear in: Current Opinion in Green and Sustainable Chemistry

Received Date: 30 November 2017

Accepted Date: 8 February 2018

Please cite this article as: P.-A. Deyris, C. Grison, Nature, Ecology and Chemistry: an unsual combination for a new green catalysis, Ecocatalysis, Current Opinion in Green and Sustainable Chemistry (2018), doi: 10.1016/j.cogsc.2018.02.002.

This is a PDF file of an unedited manuscript that has been accepted for publication. As a service to our customers we are providing this early version of the manuscript. The manuscript will undergo copyediting, typesetting, and review of the resulting proof before it is published in its final form. Please note that during the production process errors may be discovered which could affect the content, and all legal disclaimers that apply to the journal pertain. 


\title{
Nature, Ecology and Chemistry: an unsual combination for a new green catalysis, Ecocatalysis
}

\author{
Pierre-Alexandre Deyris, Claude Grison* \\ Laboratoire de Chimie Bio-inspirée et d'Innovations Ecologiques, ChimEco, UMR 5021 CNRS - University of \\ Montpellier, Cap Delta, 1682 Rue de la Valsière, 34790 Grabels, France \\ *Corresponding author: Claude Grison, claude.grison@cnrs.fr
}

\begin{abstract}
Despite the enforcement of European regulations, the dissemination of metal trace elements in nature is evolving, while the depletion of mineral ressources is alarming. The aim of Ecocatalysis is the implementation of breakthrough innovation and crossdisciplinary research in ecological restoration, organic chemistry and green catalysis to overcome this paradox. Ecocatalysis focuses on the ecological rehabilitation of mining sites by phytoextraction, treatment of industrial effluents by remedial phytotechnology, named rhizofiltration. Based on the ability of specific plants to concentrate metals, we address the transformation of plant-derived transition metals to green catalysts. The structure, activity, selectivity and recyclability of ecocatalysts are showcased in selected reactions, such as oxidations, reductions and coupling reactions.

The concept of Ecocatalysis provides catalytic and ecological tools for tomorrow's chemistry, based on the recycling of primary and strategic metals to create scientific and economical values. It offers pioneering solutions to initiate an unprecedented program in green catalysis.
\end{abstract}

\section{Keywords}

Ecological rehabilitation, phytoextraction, rhizofiltration, ecological recycling, ecocatalysis, sustainable chemistry 


\section{Introduction}

Intensive mining and industrial activities are responsible for the pollution of soils and aquatic systems with metal trace elements (TEs). TEs are some of the most harmful compounds for human health and environment. They are not biodegradable; they persist in organisms and contaminate ecosystems, soils, rivers, water tables, floodplains, and agricultural lands (Batty and Hallberg, 2010). Protecting water resources against these forms of pollution is a global challenge. While regulations toughen, the current treatments of brownfields and effluents in industrial and mining sectors are unsatisfactory. They generate new waste, which is undesirable. Priority is given to an innovative approach for effective, fair and sustainable management of the water polluted by TEs.

While TEs are increasingly accumulated within the environment, the geoeconomy and geostrategy experts at the European level published an alarming work on the "strategic minerals rush", which leaves mineral supplies perilously short in Western nations (Georghiou et al., 2011). Access to strategic and primary minerals has become critical in terms of depletion of resources, and also because they are held by a small number of politically unstable countries. Noble and transition metals like $\mathrm{Rh}, \mathrm{Pt}, \mathrm{Pd}, \mathrm{Ni}, \mathrm{Zn}, \mathrm{Cu}, \mathrm{Cr}, \mathrm{Mn}, \mathrm{Co}$, etc. are essential for many chemical processes (Hunt et al., 2015) creating a great value for European industry.

\section{Ecocatalysis, a new approach in green catalysis}

Recently, Grison et al. have studied the development of a series of novel approaches for the recycling and reuse of vital minerals for industrial chemistry, linked with the remediation, rehabilitation, or fully-fledged ecological restoration of contaminated soils on mining sites (Grison, 2015a; Losfeld et al., 2015a, 2015b, 2015c). Taking advantage of the remarquable capacity of certain land plants to hyperaccumulate transition metals into shoots and leaves, the authors have addressed the direct use of metals derived from contaminated plant waste as supported "Lewis acid" catalysts, oxidizing and reducing reagents in organic chemistry for the preparation of biomolecules. This was the first chemical recovery of new phytoextraction technologies. Recycling of waste from contaminated plants is the starting point of an unprecedented concept in chemistry, called "ecocatalysis" (Figure 1) (Grison, 2015b).

\section{Figure 1: Phytoextraction and ecocatalysis}

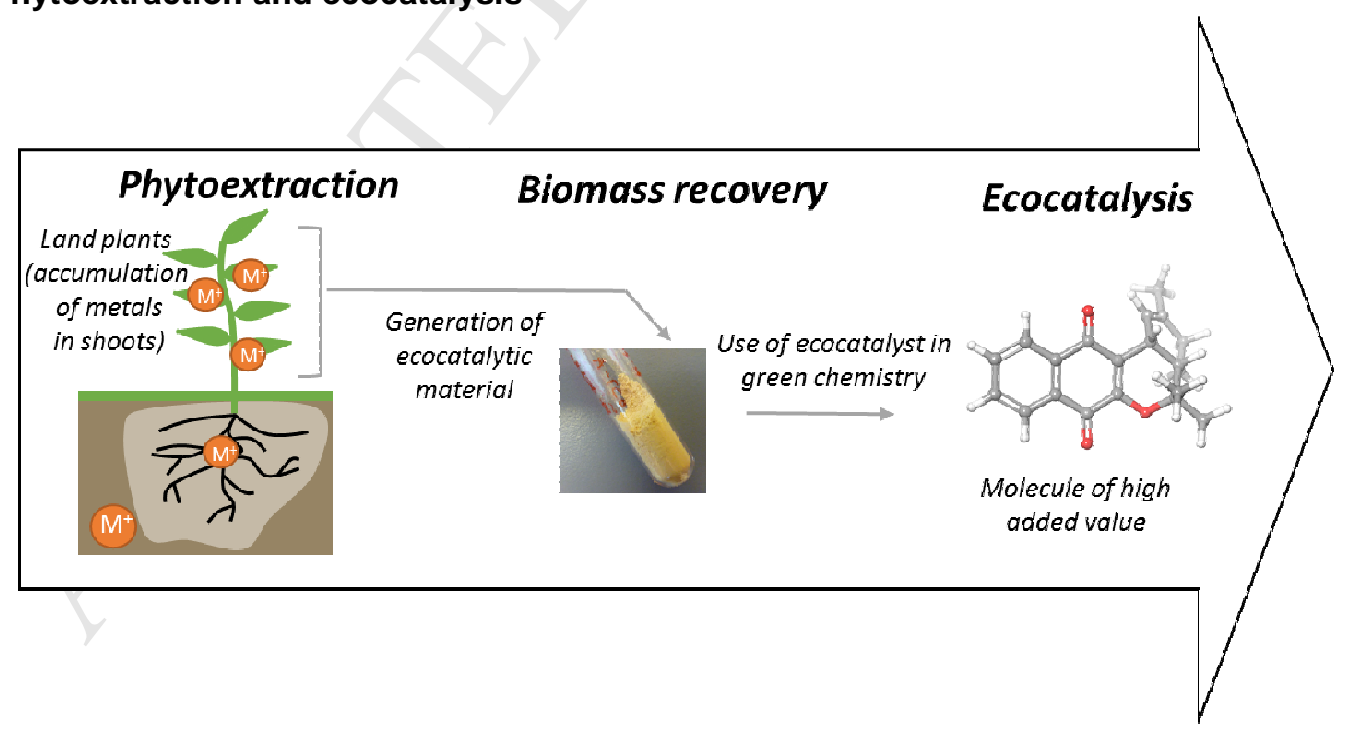

The first results showed that ecocatalysts (called Eco-M) are more efficient and selective than traditional homogeneous and heterogeneous catalysts. For example, Eco-Ni is 7.6 times higher than conventionnal $\mathrm{NiCl}_{2}$ for the synthesis of Monastrol, a potential anti-cancer agent (Grison et al., 2013). The polymetallic systems obtained from the biomass produced by phytoextraction are original. They permit new associations of chemical species such as $\mathrm{CaMg}_{2} \mathrm{Cl}_{6} \cdot 6 \mathrm{H}_{2} \mathrm{O}, \mathrm{KMgCl}_{3}, \mathrm{~K}_{2} \mathrm{ZnCl}_{4}$, (Deyris et al., 2017), powerful synergetic effects, and ideal microstructures: stable nanoparticles of $10-20 \mathrm{~nm}$, stabilization of transition metal on plant's mineral matrix 
(Garel et al., 2015). They are also more efficient in terms of chemo- and regio-selective activity, than traditional catalysts in multicomponent, domino and selective reduction reactions (Escande et al., 2015b, 2017b). In addition to this, the oxidizing capacity of Eco-Mn is one of the most amazing properties of ecocatalysts: With the same ecocatalyst, it is possible to perform a selective alkene epoxidation reaction or an oxidative cleavage reaction to obtain the corresponding aldehyde by a simple adjustment of the reaction conditions. This result is proving to be particularly interesting, as it may provide an alternative to the use of traditional oxidative cleavage reagents, which are often toxic and environmentally hazardous (Escande et al., 2015a, 2017a).

Ecocatalysts can also be used to realize synthetic transformations of biomass, thus giving access to molecules with high added value for fine and industrial chemicals such as perfumes and cosmetics industries. Functionalised aromatic heterocyclic compounds (Clavé et al., 2016b, 2017), key intermediates of various industrial chemical processes (Grison, 2015b), and biopesticides (Escande et al., 2015b) are interesting targets too, which can be obtained by using ecocatalysts. The synthetic possibilities of ecocatalysts far exceed the originally planned framework. The development of this new concept is creating a paradigm shift in sustainable and green catalysis: metallic waste is becoming an efficient, new catalytic system (Ferrand, 2014).

These pioneering results, revealed the extraordinary potential of catalysts derived from phytoextraction. The first ecocatalysts (Eco-Zn, Eco-Ni, Eco-Mn) stemmed from the use of metal hyperccumulating plants (Grison, 2015b). However, these plants are very specific, rare and are often classified as protected native species (Raskin and Ensley, 2000); their crop is delicate, complex and they grow slowly. The Ecocatalysis concept can now be extended to available and abundant aquatic plants, which show great genetic adaptation for surving in metal stress conditions and for phytoaccumulating metals quickly. These conditions will be more appropriate for chemical catalysis (Clavé et al., 2016b, 2016a, 2017). In addition, it becomes possible to recover strategic noble and transition trace metal elements $(\mathrm{Cu}, \mathrm{Pd})$, which cannot be obtained through phytoextraction from leaves.

In order to achieve these aims, an unexplored interdisciplinary research has been developped in vegetablebased biomaterials chemistry and catalysis. Another remedial phytotechnology, namely rhizofiltration (collecting trace metals in plant's roots) has been studied in order to design the next-generation ecocatalytic materials (Figure 2). In addition to their scientific and economic interest, these new materials should be better in terms of performance and durability toward wastewater treatment and their catalytic activities.

\section{Figure 2: Rhizofiltration and ecocatalysis}

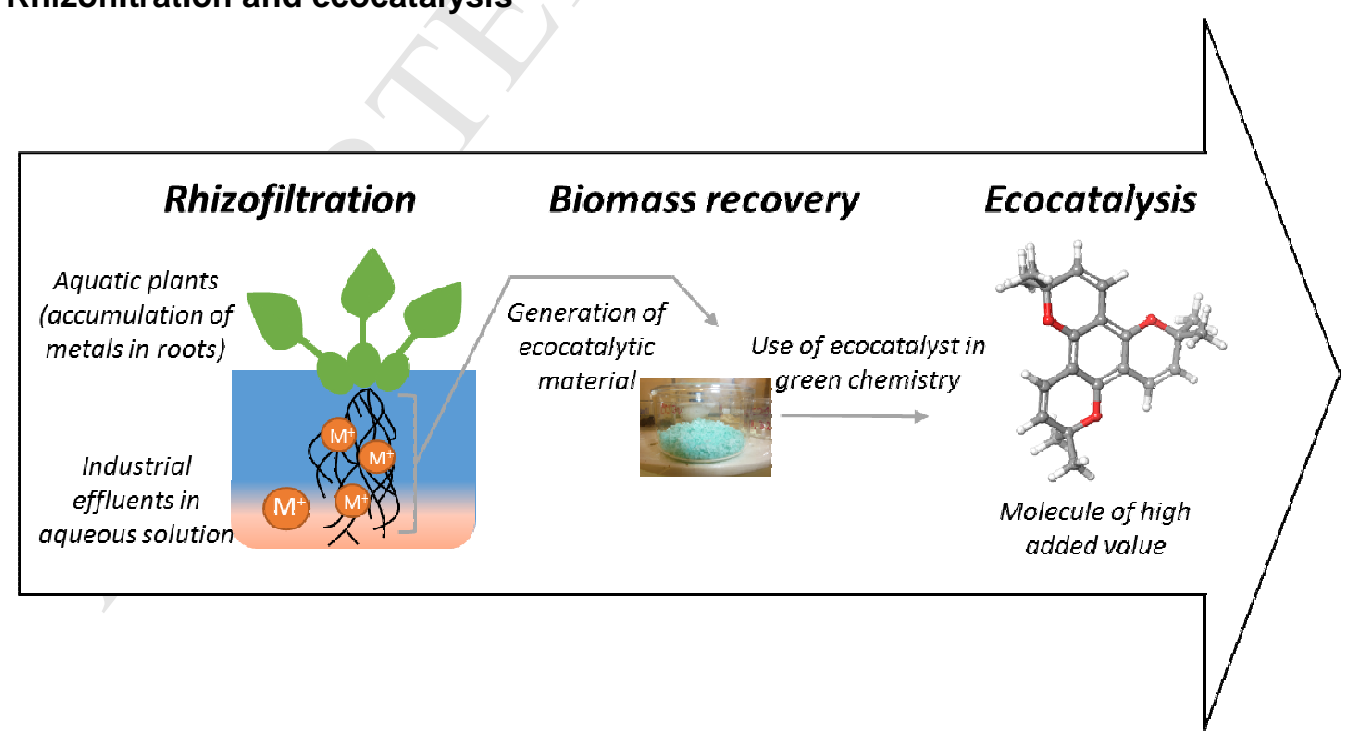

This inventive combination incorporating rhizofiltration/ecocatalysis is a real opportunity for the development of new generation ecocatalytic materials. First, this tandem is attractive in terms of chemical diversity. It overcomes the limits of phytoextraction and gives the possibility of preparing the first Eco-Pd. Secondly, the new ecocatalysts exhibit mineral composition, which is optimal in the area of catalysis. It is clear that this 
approach, which is bio-based and bio-sourced, at the frontiers of chemistry and ecology, is original, highly innovative and can play a significant role in recycling catalysts.

\section{- Rhizofiltration of Cu-contaminated effluents: A superior alternative to Eco-Cu}

$\mathrm{Cu}$ phytoextraction and its recovery in ecocatalysis have been studied by Grison et al. Potential limitations have been highlighted: the variability of the $\mathrm{Cu}$ extraction rate and the $\mathrm{Cu} / \mathrm{Co}$ association for a same species in similar edaphic conditions (Lange et al., 2016), the transport difficulty of $\mathrm{Cu}$ to the aerial parts of the plant. Although envisaging the utilization of Cu-phytoextraction on an industrial scale is tough, it is not the same case for rhizofiltration. Authors reached to prepare Eco-Cu catalysts with $10.3 \mathrm{wt} \%$ of $\mathrm{Cu}$ after six days of exposure to a $\mathrm{Cu}\left(\mathrm{NO}_{3}\right)_{2}$ solution (six experiments repeated on four aquatic and semi-aquatic species)(Clavé et al., 2016b). The abundance of Cu-contaminated effluents worldwide and their risk to contaminate aquatic systems are two strong motivating factors to develop this research area. In addition, there are other sources of pollution - i.e. agricultural, industrial and domestic - generated by frequent uses of $\mathrm{Cu}$ (distribution pipes, electric cables, algicides, anti-fungal treatments, etc.), which can also be the target of the methodology.

The synthetic potential of Eco-Cu thus generated has been studied. Preliminary ecocatalysis trials show very promising $\mathrm{N}$-arylation catalytic behaviour in Ullmann coupling. From these studies, it may be concluded that the new catalytic system shows a very promising activity in the arylation of nucleophiles. Described chemistry demonstrated that Eco-Cu catalysts are original and show valuable physicochemical properties, especially regarding their polymetallic composition. Eco-Cu catalysts offer unexplored potential for coupling reactions, especially those derived from rhizofiltration. Eco-Cu-catalyzed $\mathrm{C}-\mathrm{N}$ and $\mathrm{C}-\mathrm{O}$ bond-forming reactions are interesting methods for the synthesis of tertiary amines and aryl ethers (Clavé et al., 2016a). Moreover, significant differences of properties and activities were observed between $\mathrm{Eco}-\mathrm{Cu}$ and conventional $\mathrm{Cu}$ catalysts. Eco-Cu appeared as highly active catalysts for azide-alkyne cycloaddition reaction with lower $\mathrm{Cu}$ quantity compared to known copper catalysts (Clavé et al., 2016b).

\section{- Choice of Industrial Effluents Enriched with Pd: A Necessary Innovation}

Palladium and Platinum Group Metals (PGM) are a vital piece of the European industry. As The 2010 Nobel Prize for Chemistry recognized the implications of palladium metal catalysts as sophisticated and efficient tools to synthesize new carbon-carbon bonded structures. These methods have deeply changed methodologies for the construction of natural products, building blocks for supramolecular and medicinal chemistry, organic materials and polymers. The development of these processes is continuing to progress dramatically.

The supply of Pd and PGM for chemical companies and thus the competitiveness of European industry is a key strategic issue as $97 \%$ of Pd comes from Russia and South Africa. Ecocatalysis has recently allowed the development of greener bio-based alternatives for Pd catalysis and recycling (Figure 3).

Pd hyperaccumulating plants, and so PGM phytoextraction, do not exist. Rhizofiltration is the only ecological solution for $\mathrm{Pd}$ recycling. It is also an opportunity for the synthesis of bio-based and bio-sourced Eco-Pd catalysts from plants used in rhizofiltration. It is clear that significant differences to conventional Pd-based catalysts such as palladium (II) chloride have been demonstrated.

Figure 3: Principle of Eco-Pd catalysis

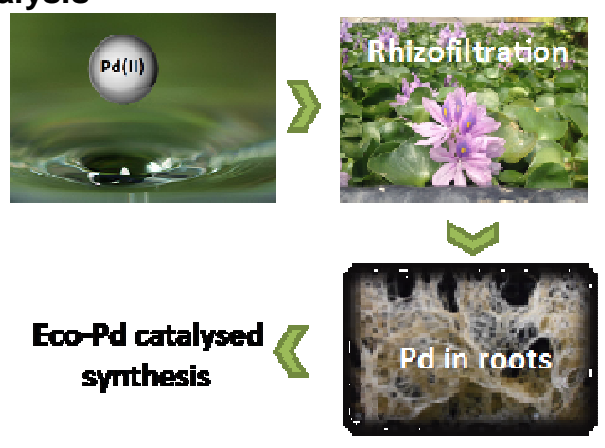

In a first step, the authors demonstrated that different plants such as Brassica juncea and Lolium multiflorum can extract and accumulate palladium which finally can be transformed in catalytic materials for Heck and 
Suzuki cross-coupling. Eco-Pd showed a higher activity without ligand and an ideal microstructure (stable nanoparticles of 10-20 nm, stabilization of Pd on plant's mineral matrix). Moreover, Eco-Pd was successfully used for the coupling of aryl chlorides and areneboronic acids (Garel et al., 2015). However, this catalyst was difficult to recover and reuse, which could induce contamination of heteroaryl products. Moreover, the production of root biomass is limited by the nature of plants, the reactivity of Eco-Pd in heterocylic series is unknown and the reaction conditions must be improved in terms of green chemistry (solvent, reaction conditions, recycling and sustainability of sourcing).

In a second step, Grison's group described the use of Eichhornia crassipes (water hyacinth) to bioconcentrate $\mathrm{Pd}$ with the aim of increasing the root biomass and the capacity of Eco-Pd production. This allows to perform scale-up synthesis and to realize the study of Eco-Pd recycling-reusing in the delicate case of heterobiaryl compounds. They reported a novel bio-based Eco-Pd to perform hetero Suzuki coupling in green conditions. The preparation, characterization, reactivity and reusability of Eco-Pd, as well as Pd leaching, have been described. For the first time, the preparation of Eco-Pd obtained by rhizofiltration of post-reaction based on circular system was shown (Clavé et al., 2017). It was demonstrated that homogeneous catalysts involving precious metals can be easily recycled via eco-friendly and efficient technology based on rhizofiltration. In other terms, it has been shown that ecological recycling can be considered as a "resource" of metal catalysts.

\section{Conclusion}

The concept of ecocatalysis, introduced by our group, represents a true alternative to traditional catalysis based on the remarkable capacity of certain plants to hyperaccumulate transition metals in shoots or leaves. Metals derived from contaminated plant wastes were sucessfully used as supported "Lewis acid", oxidizing, reducing and coupling catalysts in organic chemistry for the preparation of biomolecules. This strategy constituted the first chemical recovery of new phytotechnologies. Ecocatalysis is a new approach of green catalysis, which can address scientific innovation in green and sustainable chemistry, rehabilitation of mining sites, water depollution and compete against the depletion of mineral resource while creating ecological and economic value. The methodology opens the opportunity for the large-scale synthesis of industrial targets at the frontiers of sustainable processes and phytotechnologies.

This interdisciplinary approach will implement ground-breaking ecological solutions, which will in turn create innovative tools for the ambitions of tomorrow's green chemistry and environmental management.

\section{Acknowledgements}

This work was supported by the Centre National de la Recherche Scientifique (CNRS) and the University of Montpellier.

\section{References}

Batty, L. C., and Hallberg, K. B. eds. (2010). Ecology of Industrial Pollution. Cambridge: Cambridge University Press doi:10.1017/CBO9780511805561.

Clavé, G., Garel, C., Poullain, C., Renard, B.-L., Olszewski, T. K., Lange, B., et al. (2016a). Ullmann reaction through ecocatalysis: insights from bioresource and synthetic potential. RSC Adv. 6, 59550-59564. doi:10.1039/C6RA08664K.

* Clavé, G., Garoux, L., Boulanger, C., Hesemann, P., and Grison, C. (2016b). Ecological Recycling of a BioBased Catalyst for Cu Click Reaction: a New Strategy for a Greener Sustainable Catalysis. ChemistrySelect 1, 1410-1416. doi:10.1002/slct.201600430.

This work demonstrates for the first time that homogeneous catalysts can be easily recycled through an eco-friendly and efficient technology based on rhizofiltration.

** Clavé, G., Pelissier, F., and Campidelli, S. (2017). Ecocatalyzed Suzuki cross coupling of heteroaryl compounds. Green Chem 19, 4093-4103. doi:10.1039/C7GC01672G. 
Authors present the first results obtained for the ecocatalyzed Suzuki-Miyaura cross coupling of heteroaryl compounds under homogenous conditions, compatible with green chemistry and without ligands or additives. An eco-friendly and effective recycling process of the homogeneous $\mathrm{Pd}$ catalyst that can be repeated without loss of catalyst's activity.

Deyris, P.-A., Gorazureta, G., Petit, E., Legrand, Y.-M., Diliberto, S., Boulanger, C., et al. (2017). Biosourced polymetallic catalysis: A surprising and efficient means to promote the Knoevenagel condensation. Front. Chem. in press

Escande, V., Lam, C. H., Grison, C., and Anastas, P. T. (2017a). EcoMnOx, a Biosourced Catalyst for Selective Aerobic Oxidative Cleavage of Activated 1,2-Diols. ACS Sustain. Chem. Eng. 5, 3214-3222. doi:10.1021/acssuschemeng.6b02979.

${ }^{* *}$ Escande, V., Petit, E., Garoux, L., Boulanger, C., and Grison, C. (2015a). Switchable Alkene Epoxidation/Oxidative Cleavage with $\mathrm{H}_{2} \mathrm{O}_{2} / \mathrm{NaHCO}_{3}$ : Efficient Heterogeneous Catalysis Derived from Biosourced Eco-Mn. ACS Sustain. Chem. Eng. 3, 2704-2715. doi:10.1021/acssuschemeng.5b00561.

This is the first contribution of ecocatalysis for oxidation reactions and the first results obtained with Eco-Mn. Comparison of its properties to those of conventional heterogeneous catalysts highlighted the superior catalytic activity of biosourced Eco-Mn.

* Escande, V., Poullain, C., Clavé, G., Petit, E., Masquelez, N., Hesemann, P., et al. (2017b). Bio-based and environmental input for transfer hydrogenation using EcoNi(0) catalyst in isopropanol. Appl. Catal. B Environ. 210, 495-503. doi:10.1016/j.apcatb.2017.04.023.

The article describes a green and straightforward preparation of $\mathrm{EcoNi}(0)$ nanoparticles. The $\mathrm{EcoNi}(0)$ demonstrates a high efficiency and selectivity for the transfer hydrogenation of carbonyl compounds, including challenging aldehydes and $\alpha, \beta$-unsaturated carbonyl compounds.

** Escande, V., Velati, A., Garel, C., Renard, B.-L., Petit, E., and Grison, C. (2015b). Phytoextracted mining wastes for ecocatalysis: Eco-Mn®, an efficient and eco-friendly plant-based catalyst for reductive amination of ketones. Green Chem 17, 2188-2199. doi:10.1039/C4GC02193B.

This article reportes the first example of reduction reactions catalyzed by Eco-Mn.

Ferrand, S. (2014). ANR annual report 2014. Available at: http://www.agence-nationalerecherche.fr/fileadmin/documents/2015/ANR-annual-report-2014.pdf.

* Garel, C., Renard, B.-L., Escande, V., Galtayries, A., Hesemann, P., and Grison, C. (2015). CC bond formation strategy through ecocatalysis: Insights from structural studies and synthetic potential. Appl. Catal. Gen. 504, 272-286. doi:10.1016/j.apcata.2015.01.021.

Using Eco-Pd, authors present the first results obtained for the C-C bond formation strategy through ecocatalysis. The properties of Eco-Pd show unprecedented results in Heck and Suzuki reactions, in terms of selectivity and reactivity.

Georghiou, L., Varet, J., and Larédo, P. (2011). Breakthrough technologies: For the security of supply of critical minerals and metals in the EU. Available at: http://www.foresight-platform.eu/brief/efp-brief-no181-technologies-for-eu-minerals-supply/.

Grison, C. (2015a). Combining phytoextraction and ecocatalysis: a novel concept for greener chemistry, an opportunity for remediation. Environ. Sci. Pollut. Res. 22, 5589-5591. doi:10.1007/s11356-014-31690 .

Grison, C. (2015b). Special Issue : Combining phytoextraction and ecocatalysis: a novel concept for greener chemistry, an opportunity for remediation. Environ. Sci. Pollut. Res. 22, 5589-5698.

Grison, C., Escande, V., Petit, E., Garoux, L., Boulanger, C., and Grison, C. (2013). Psychotria douarrei and Geissois pruinosa, novel resources for the plant-based catalytic chemistry. RSC Adv. 3, 22340. doi:10.1039/c3ra43995j. 
Hunt, A. J., Matharu, A. S., King, A. H., and Clark, J. H. (2015). The importance of elemental sustainability and critical element recovery. Green Chem 17, 1949-1950. doi:10.1039/C5GC90019K.

Lange, B., Pourret, O., Meerts, P., Jitaru, P., Cancès, B., Grison, C., et al. (2016). Copper and cobalt mobility in soil and accumulation in a metallophyte as influenced by experimental manipulation of soil chemical factors. Chemosphere 146, 75-84. doi:10.1016/j.chemosphere.2015.11.105.

Losfeld, G., L'Huillier, L., Fogliani, B., Coy, S. M., Grison, C., and Jaffré, T. (2015a). Leaf-age and soil-plant relationships: key factors for reporting trace-elements hyperaccumulation by plants and design applications. Environ. Sci. Pollut. Res. 22, 5620-5632. doi:10.1007/s11356-014-3445-z.

Losfeld, G., L'Huillier, L., Fogliani, B., Jaffré, T., and Grison, C. (2015b). Mining in New Caledonia: environmental stakes and restoration opportunities. Environ. Sci. Pollut. Res. 22, 5592-5607. doi:10.1007/s11356-014-3358-x.

Losfeld, G., Mathieu, R., L’Huillier, L., Fogliani, B., Jaffré, T., and Grison, C. (2015c). Phytoextraction from mine spoils: insights from New Caledonia. Environ. Sci. Pollut. Res. 22, 5608-5619. doi:10.1007/s11356-014-3866-8.

Raskin, I., and Ensley, B. D. eds. (2000). Phytoremediation of toxic metals: using plants to clean up the environment. New York, NY: Wiley. 
First ecocatalysts revealed the potential of catalysts derived from phytoextraction

Ecocatalysis has been extended to aquatic plants for phytoaccumulating metals quickly

Homogeneous catalysts involving transition metals can be recycled via rhizofiltration

The many opportunities highlight Lewis acid catalysis, green reduction and oxidation

Ecocatalysts constitute a new generation of catalysts for cross coupling reactions 